\title{
Fathers' experiences of caring for an adult child with psychosis: A qualitative study
}

\author{
Sharma, B., Green, N. \& Keville, S.
}

\begin{abstract}
Previous research exploring parental experiences of caring has highlighted both the rewarding nature and associated difficulties with this role. Within these studies the majority of parents have been mothers, resulting in minimal understanding about fathers' experiences. The aim of the current study was to explore how fathers described and made sense of their caring experiences.
\end{abstract}

Semi-structured interviews were carried out with seven participants, including six biological fathers and one step-father. Interviews were analysed using interpretative phenomenological analysis.

Five themes emerged: 'Father versus carer'; 'Change in quality of the relationship with child'; 'To share or not to share; 'Acceptance is a struggle'; and 'Mental health services: inconsistency vs. luck'. Previous research has indicated a minimal role of fathers, in contrast the current study found fathers were deeply committed to their caring role viewing this as central to being a parent, caring unconditionally for their adult child with additional needs.

Fathers can play a crucial and unconditional role in the care of their adult children. With long-term complex conditions, such as psychoses, it is important for services to recognise the contribution of fathers, to enable greater involvement whilst also offering support for them to help sustain their important caring role. 


\section{Introduction}

In the United Kingdom (UK), given approximately half of the 245,000 adult people diagnosed with a psychotic disorder have carers, around 120,000 people (36\% are parents; $65 \%$ are female) will undertake a primary caregiver role (Kuipers et al., 2010; Roick et al., 2007). Carers for people with psychosis spend an average of six to nine hours a day providing support (Magliano et al., 1998), saving the public approximately $£ 1.24$ billion a year in health care costs (Schizophrenia Commission, 2012). Research suggests that those supported by carers, achieve better outcomes; including fewer inpatient admissions and relapses, better engagement with services and treatments, and improved life expectancy (Onwumere et al., 2016).

Whilst caregiving can be a positive and mutually rewarding experience (Chen \& Greenberg, 2004) those caring for people with psychosis have the additional difficulties of dealing with the stigma, shame and social isolation associated with a mental illness (Hinshaw, 2005). Carers of people with psychosis often experience high levels of exhaustion, distress and social isolation with approximately $40 \%$ of carers reporting poor psychological functioning (Onwumere et al., 2016). Caregivers also report posttraumatic stress symptoms related to their caring role, which may have implications for their caregiving experiences and coping efforts (Kingston et al., 2015). Further, being a carer can have financial implications through reductions in working hours or giving up work to care for the person with psychosis (Yesufu-Udechuku et al., 2015). Therefore, caring for a person with psychosis is complex, often undervalued and insufficiently supported by services (Roick et al., 2007) and society.

Studies note traumatic caregiver experiences when caring for a relative with a psychosis-related diagnosis (McAuliffe et al., 2014; Raymond et al., 2017; McCann et al., 2011; Darmi et al., 2017). These studies identify the lengthy process involved in accepting and coming to terms with the diagnosis, and changes in the relationship with their child (child 
will be used to denote the parental relationship with their offspring regardless of the age of the person with psychosis). Often related to stigma, parents have a sense of responsibility, guilt and burden around their child's psychosis-related difficulties; other common themes are frustration with mental health services (Hickman et al., 2016).

Due to noted difficulties in recruiting male carers and fathers in research, these previous studies are heavily biased towards mothers (McAuliffe et al., 2014; Darmi et al., 2017). Darmi et al (2017). This is possibly due to fewer fathers attending carers' groups compared to mothers/female carers (Sharma et al., 2016), thus, decreasing fathers' accessibility to recruiting researchers. Consequently, there is minimal research on father specific experiences. One study stated this could be due to men feeling they should not talk about their experiences and feelings (Darmi et al., 2017). Reasons for difficulties recruiting fathers have tended to state this is due to not caring or wanting to be involved in supporting their child (Lamb, 2000). This has created a significant gap in the UK literature regarding fathers' caring experiences. To address this, the current study aimed to answer the following question: What are the experiences of fathers caring for an adult child with psychosis?

\section{Method}

This study focussed on exploring a deep account of fathers' lived experiences of being a carer for an adult child with psychosis using Interpretative Phenomenological Analysis (IPA). IPA offers a recognised, phenomenologically focussed approach to the interpretation of these accounts (Larkin \& Thompson, 2012).

Ethical approval was granted from the University of Hertfordshire's Health and Human Sciences Ethics Committee (LMS/PGR/UH/02801). Confidentiality and consent were considered and maintained throughout the study. 


\section{Researcher characteristics}

The first and second authors have experience of working in psychoses services including working with families. The third author is a carer (albeit non-psychoses related) alongside working in clinical psychology training and qualitative research.

\section{Recruitment}

A purposive sampling method was used to recruit fathers caring for a child with psychosis. Carers' organisations and groups in the voluntary, charitable and third sectors were approached, as well as the Experts by Experience Committee on the Hertfordshire doctoral psychology course. Interested participants contacted the first author and suitability determined through an informal telephone conversation; participants had to be a father or father-figure caring for an adult child (age 18+) with a psychosis-related diagnosis, and fluent in English.

\section{Participants}

All seven participants who contacted the researcher were recruited into the study: six biological fathers were caring for one child, and one stepfather for two children, with psychosis-related difficulties. All participants had other children. Only one participant lived with the child they cared for. All participants had been or were currently the main earner in their families. Three participants were currently employed and three were retired: jobs included lawyer, engineer and bank manager. One participant was unemployed due to a longterm disability. Participants had been carers for between two and thirty years, with an average length of fifteen years. Participants spent an average of 17 hours per week caring for their child. All fathers had had contact with National Health Service (NHS) mental health services 
in the United Kingdom through their child's contact with services. Two of the participants had previously had psychological therapy in the form of family interventions (FI). The demographics of the recruited participants is presented in Table 1.

(Insert Table 1 here)

\section{Procedure}

Six participants were interviewed at their home and one in a community centre. Interviews lasted between 60 and 90 minutes and were audio-recorded and later transcribed. The interview schedule was developed with expertise from the research team and through carer consultant, who reviewed the information sheet, consent form and undertook a pilot interview. Sample questions included: What sense do you make of your child's psychosis? How do you support your child? How has your child's psychosis affected your relationship with them over time? How has caring for your child impacted you in other areas of your life? How does being a father affect your caring role? What has your experience been of professional care for your child? What do you think could be done better to help you in supporting your child?

\section{Analysis}

Interviews were analysed by the first author using IPA (Smith et al., 2009). Each transcript was read and listened to multiple times noting emergent themes, reflections, and linguistic, semantic and conceptual aspects of the language; then, utilising abstraction, numeration and polarization, themes were identified in each transcript before compiling superordinate and subordinate themes across all transcripts (Smith et al. 2009). The research team discussed the analysis process throughout to ensure validity (Yardley, 2008). For the purposes of this paper, to present an overview of the results, the subordinate themes are incorporated within superordinate themes (further detail can be found in Sharma (2018)). 


\section{Results}

Five themes emerged from the data:

- '....you're a father first': Father versus carer

- I treat him more like a child now than an adult': Change in quality of relationship with child

- '...when you get friends like that, who wants enemies?': To share or not to share

- Acceptance is a struggle

- Mental health services: inconsistency versus luck

The themes will now be presented.

\section{'....you're a father first': Father versus carer}

Most of the participants viewed the caring role as part of being a good parent or 'father':

'....you're a father first, you only become a carer because you have to...first of all, you're a parent, and if you're a good parent, you should be a good carer.' (Patrick)

The quality of the caring role was governed by the quality of parenting as a father, with a lifelong commitment conveyed to this role and relationship with their adult child. Indeed, participants spoke of their unconditional love and support throughout, regardless of the situation(s). For example, 
'They're always going to be your children and therefore, if any of them had any problems, no matter what it was... you'd be there for them and try and help them.' (Leo)

For some participants, the paternal instincts honed from knowing their child's 'history' had been crucial in establishing their carer role; they knew their child better than anybody else and used this to guide their child:

'You know their history, you know some of the things they've done and things they've struggled with, you're able to help direct them in certain ways where maybe other people can't.' (Leo)

However, emphasised via the term 'hinders', there were also difficult aspects with the dual role of being a father and carer:

'I think it hinders you because you're too close.' (Paul)

Despite this, participants spoke of their unconditional love and support no matter what the situation, commenting that there was no end to what they would do for their child, regardless of the psychosis.

'...because I'm his father, I want to try and help him as much as I can...If he needs help or wants guidance or like we've got to take him to hospital, then I will do that (Bryan) 


\section{'I treat him more like a child now than an adult': Change in quality of relationship with}

child

Many participants described the pull of going from an 'emotionally' close relationship to a 'distant' one, and vice versa, as well as fluctuations between the two. This seemed dependant on their child's mental health state and whether they were in hospital or taking drugs.

'It's sort of bittersweet really, sometimes I'm really close to him emotionally. There are other times where I feel as though I don't recognise him at all, you feel quite distant. So it's very extreme to be honest.' (Paul)

The terms 'bittersweet' and 'extreme' highlighted just how wrenching fluctuations within the proximity of their relationship were. Many participants strongly desired to maintain a close relationship with their child and attained this through caring. It should be noted that whilst never directly stated (and, thus, not forming its own superordinate theme) there were undercurrents of sadness throughout all but the 'father versus carer' theme. This was particularly highlighted in the following quotes when Leo talked of it being 'horrible' and 'unfortunate' and Patrick stated he was told his son '...should not live here' (with him):

'I treat him more like a child now than an adult because I'm having to say, "Wyatt have you done this? Wyatt have you done that?" And it's upsetting because I'd like to treat him as an adult like I do with the other two, but it is difficult...So Ifeel like I'm on his back all the time which is unfortunate... Horrible. I don't like it. '(Leo) 
Having to 'treat him more like a child' elucidated a sense of helplessness and powerlessness in their caring role as their 'child' was not 'an adult' and, thus, beyond direct control. Further, there was a sense of wanting to protect their child in all circumstances, even if it put their own self or wellbeing at risk. For example, Patrick stated:

'...he came into a room while I was sitting down, and punched me in the face and just run off... another time he had a knife...they [police] came and arrested him although I told them that he had a mental health [problem].'

Perhaps, this made being a father and protecting their child so difficult - their child always came first despite physically aggressive behaviour ('punched', 'knife') which was to the father's own detriment in the context of unpredictable and unsafe behaviour. Patrick went on to say:

'Just seeing that happen was particularly difficult for me because at that time, I was not only trying to do whatever I can to support myself with my disability ... but I was told because he was getting physical, that he shouldn't live here.'

Patrick's experience reflected the real risk of harm to parents in caring for their child within acute episodes of psychosis when aggression was present; yet, alongside this was an understanding that underpinning the violence was their child with a 'mental health problem'. Indeed, this underlying awareness of mental health issues was highlighted when risk of harm did not involve others but involved their child risking losing their life through suicide: 
'...when someone wants to commit suicide, there's just nothing- you just feel like there's nothing you can do.' (Paul)

The contrast of an innate drive to 'protect' with the repetition of 'there's nothing..... nothing you can do' emphasised the powerlessness of their position when caring for an adult child with psychosis. Developing this further, Ron expressed his desire to protect his son by keeping any sense of loss to himself:

'He and I don't tend to go out. Even after he got the psychosis, we used to go out occasionally and watch football or cricket. But, over the last say five years he's found it difficult to go to football and cricket matches. I do miss doing that. It would be nice to take him and I would probably go more often if the opportunity arose, but it doesn't.' (Ron)

Again, the enduring nature of this changing relationship impacted on the proximity of closeness, and an indirect sense of sadness was striking when Ron stated 'I would probably go more often if the opportunity arose, but it doesn 't'. This raised issues of how the fathers accessed their own emotional support when undertaking their caring roles which is explored in the next theme.

\section{‘....when you get friends like that, who wants enemies?': To share or not to share}

Most participants found carers' groups beneficial, yet despite this utility, Neil found it difficult to balance regularly attending the group with other responsibilities such as work. 
'...we went to quite a few carer peer support groups initially, which was quite useful, but stopped after a while. I think my wife continued going to them, I didn't, and maybe because I was busy at work or whatever.' (Neil)

Interestingly, some participants commented they needed to protect themselves from the burden of hearing other carers' experiences; perhaps there was an underlying sense of guilt to this positioning evoked via the term 'selfish'

'But I think the problem we have sometimes is you get the sort of selfish attitude that I've got... we've got our own problems without listening to everybody else's.' (Neil)

However, this 'selfish' positioning seemed a necessity, given they had their 'own problems'; yet, perhaps it also increased the risk of isolation. Indeed, several participants shared a sense of family and friends becoming more distant, both emotionally and physically.

'...they have either accepted the fact that we're going to talk about it and have stayed friends or can't cope with what we're saying or the situation itself or maybe we just bore the pants off them... and they have tended to drift away.' (Victor)

'They all know but they don't take it on board. One of my friends turns around and said, "Why don't you turn the phone off?" Because he [his son] will get so anxious he could do anything. "Oh, well, I'd turn my 
phone off." That's his reaction. So when you get friends like that, who wants enemies? They don't appreciate mental illness.' (Bryan)

Comparing the dismissive and unhelpful answers of friends as ones that 'enemies' might give, illustrated just how hard and frustrating it was for Bryan when people did not understand. It was, therefore, unsurprising that participants struggled to talk about their experiences with those that did not understand the nuances around caring for a child with psychosis. At such times, perhaps, it might be crucial to enable fathers to connect with other fathers with similar caring experiences:

'...you are meeting other people who are going through the same situation' (Paul)

Other aspects of the caring role emerged within the participants transcripts, highlighted in the next theme which noted the enduring nature of caring for an adult child with psychosis.

\section{Acceptance is a struggle}

A sense of helplessness emerged when participants described that, no matter how much they did for their child, it was never enough:

'...there's nothing really you can do or say to that child that's helping in any way, it becomes so really difficult because there's nothing that you're doing to try and help the situation. It's there and that's what we got to cope with.' (Paul) 
The enduring quality emerged in the phrase, 'it's there and that's what we got to cope with'. Despite this knowledge there were indirect senses of powerlessness and helplessness as, whilst knowing the psychosis was present, they still:

'...don't make any sense of it. It's difficult. It's something I never come across before.' (Leo)

It seemed the journey to acceptance enabled Bryan to be more compassionate and understanding to his son's suffering.

'...it's only in the last few years that I've accepted that he has an illness that causes problems with him...It's me accepting the fact that he has a problem and it's not just the drugs.' (Bryan)

Again, there was an indirect sense of sadness when Bryan said 'it's only in the last few years that I've accepted.' It was further evident within all the transcripts with the acceptance their child would probably never have the lives they had hoped for them.

'Obviously I was very disappointed that he couldn't do what other normal boys would do and that disappointment was really tremendous for me.'

(Bryan)

The repetition of 'disappointed' and 'disappointment' coupled with the term 'really tremendous', highlighted the severity of this realisation for Bryan. Neil also spoke of this paternal hope being 'dashed'. 
'...expectations have been dashed as a father, maybe it's a gender thing, but you probably have high expectations. As a father what you planned for them is to grow up, get married possibly, have a partner anyway, possibly have children, have a house, etc. So that isn't going to happen, you don't sort of give up on hope completely, but you do feel a bit frustrated and it does get quite depressing sometimes.' (Neil)

A more direct sense of sadness became evident through Neil's acknowledgment that 'it does get quite depressing sometimes'. All participants spoke of a sense of grief for the loss of the life their children could have had, had it not been for the psychosis. Given acute episodes occur in the context of an enduring condition, mental health care services featured in all the transcripts forming the final theme.

\section{Mental health services: Inconsistency versus luck}

In relaying their experiences, the proximities of participants' experiences with mental health services ranged from thorough and consistent to neglectful and disappointing. For the parents, the hope services could help was experienced from the outset, and as the efficacy of the provision could not be predicted, this perhaps reflected an element of luck in the type of service the participants' children received.

'...we were extremely lucky, it was the first episode psychosis team and they did absolutely everything for him, it was fantastic. But at the end of two years - time's up. You've got to go into somewhere else and it just failed after that.' (Bryan) 
Whilst psychosis was enduring the experience of quality care was not when provision had to 'end' due to service limitations meaning 'it just failed after that'. Other positive elements emerged with participants valuing the support that was available to them and their partners through being included in their child's care. Thus, treatment involving the family helped everyone make sense of the psychosis and, in turn, the way in which parents supported their child.

'... a therapist assigned to the family, and he'd ring us up or we'd go and see him - he was very, very good. Very well supported it was.' (Leo)

When it was valued, it was highly valued, as demonstrated in Leo's repetition ('very') when he says 'very, very good' and 'very well supported'. Yet, lack of continuity and communication were identified as factors that hindered care; with this, participants stated all they wanted was for services to appropriately support their child, which in turn supported them as 'carers'.

'My feeling is that everything needed to be on Jo because as a carer, I think we only go to services for support for ourselves if we need it. I think [knowing he is supported] would give me peace of mind.' (Patrick)

Patrick's need for "peace of mind" evoked an almost constant worry about his son's safety which he believed could be alleviated via 'support' for his son. Accessing support had a futile quality to it, almost representing a battle, when Bryan stated: 
'I have complained bitterly that no one had gone to see him or been in touch with him for three weeks. I specifically stated that the CPN should've been there. Following day, the woman phoned Ken up and said, "Your parents have complained about me so I've got to come and see you." Really, why didn't she go and see him off her own back? Why do I have to complain to get that?' (Bryan)

Indeed, Bryan's questioning stance almost highlighted his disbelief in the lack of care and concern for his son. Other participants described pushing to be involved in their child's care, but due to the on-going complication of their child being an adult, confidentiality and, thus, involvement became more difficult.

'Including us is good, it is a positive thing. Because obviously he was a young adult, so we had to sort of push for that all the time, that's quite energy intensive... because we manage to articulate well and we were prepared to support Daniel, and it clearly takes the pressure off services if we're supporting him.' (Neil)

There was a sense that an ability to 'articulate well' was crucial in services accepting parental support for the benefit of their child. Given that participants often spoke of needing to step in because their children were in no position to advocate for themselves, one wonders what happens to adults without active paternal and parental buffering. Thus, rather than paternal carers having to constantly chase and follow up mental health services, there was a sense that this process should be inclusive for the benefit of all.

\section{Discussion}


In exploring the experiences of fathers caring for an adult child with psychosis, five themes emerged. Participants spoke of a range of experiences, reflecting the various ways in which they navigated their caring roles, the tensions in being a paternal carer, and their relationship with mental health services.

Being a paternal carer is seen both positively and negatively due to the emotional connection and proximity of the relationship with their child; describing an enduring life-long loving and responsible relationship with their adult child. This gave meaning to both their fathering and caring role (McAuliffe et al., 2014). It is important to emphasise that traditionally caring has been seen as a feminine practice (Doucet, 2004), with an assumption that men do not care or want to participate in caring (Lamb, 2000). Yet, this study supports the shifting in parenting that has occurred over the past 30 years highlighting the emergence of the co-parent father, taking on more caring responsibilities (Cabrera et al., 2000); consequently, challenging earlier views of the father role. Policy makers and service providers should be mindful that existing structures may hinder this progress given there is the potential for continued shortcomings in government policy, workplace culture and the gender pay gap (Wall and Arnold, 2007) to maintain overall support for caregiving being focussed on mothers, thus, excluding fathers as a valuable source of support. Indeed, Cabrera et al. (2000) suggest that new theoretical models of parenting need to be formulated to include and understand the shifts in family structures and notions of what it means to be a father across cultures.

The role of fathers in caring for adult children with enduring and complex needs highlights a difficult position for fathers. In this study, despite an overall sense that carers groups are helpful, not all participants regularly attend them; perhaps understandably as they report being the only male carer in the group. For men, speaking in predominately female groups adds an additional layer which can compound the stigmatisation that already occurs 
around psychoses (Spandler et al., 2013). Furthermore, research purports that men generally struggle to express their emotions at the best of times (Spandler et al., 2013), yet, this is not supported in the current study where the fathers articulately expressed nuanced and complex emotional difficulties. Whilst the fathering role is evolving, perpetuated by a higher number of mothers remaining in the workforce (Doucet, 2004; Wall \& Arnold, 2007; Rochlen et al., 2010), six of the seven fathers in the current study identify themselves as the main breadwinners. Thus, there is a practical reason why attendance at carers' groups is not possible and, as the findings in the current study highlight, fathers remain committed to caring for their child alongside managing work commitments.

Additionally, the enduring nature of the psychosis appears to have parallels with the enduring nature of caring; even when participants are not physically close to their child, they care with the intensity and input required of a child in their early years. Unfortunately, as they no longer have parental rights, they no longer have the level of control required to help manage their adult child's complex needs despite needing to provide care at the level a child required as highlighted in the theme 'I treat him more like a child now than an adult'. It is unsurprising, then, that participants express an enduring sense of helplessness; despite their input it is never or could never be enough to enable their child to regain and maintain independence; their children are adults after all. Further, despite the length of time participants had been in their caring role, they still struggle to make sense of their child's psychosis - having this may help them feel more in control of the illness and less stressed (Onwumere et al., 2008); in the current study gaining knowledge and understanding facilitated acceptance for these fathers.

\section{Clinical implications}

This study's findings reveal several clinical implications on multiple levels: 
Service-level implications

Given fathers in this study are committed to caring for their adult children, shifting assumptions about fathers embedded in UK society that fathers are uninvolved and do not care (Lamb, 2000) will likely involve more direct approaches by clinicians, achieved via more routine explorations of the involvement of fathers in caring. It can also involve setting up services in a manner that supports fathers' involvement. Services generally work within typical working hours, Mondays to Fridays. Yet, work commitments, can create difficulties accessing these interventions. This may limit the types of interventions offered particularly if a key person is absent. Thus, services could be more flexible by having out-of-hours clinics, working within the familial home, or using phone conversations or email.

Participants in the study suggested improvements in services beyond the initial diagnosis via psycho-education and availability of information as the illness progressed. This would reflect the different levels of support and information needed by fathers at different points in their caring roles (Kuipers et al., 2010).

General practitioners (GPs) are potentially the biggest source of individual support for carers. They can put alerts on service users', and male and female carers' records to ask about health needs and facilitate signposting to carer support and resources. Seeing the same GP each time the carer visits the surgery would promote continuity of care. It also identifies the need for training and raising GPs' awareness to aid early detection and intervention for both male and female carers to support them in the initial stages of their child's psychosis, enabling them to continue to effectively support their child.

\section{Family-level implications}


In this study fathers demonstrate a deep commitment to their child wanting to maintain close relationships with them. Yet, the condition can limit the types of activities fathers undertake by moving them away from leisure activities to basic caring duties; impacting on the quality and proximity of their relationship. In line with NICE (2014) guidelines, extending interventions to more explicit family-based interventions seems beneficial, particularly in facilitating the family to more openly process losses. For example, there is a strong evidence base for Family Interventions in reducing relapse and carer burden (NICE, 2014) which may help support fathers in their caring role, and may be important given access to these interventions remains low (Royal College of Psychiatrists, 2019).

Further, there is emerging potential for the use of Open Dialogue Interventions (where contact is made with families and networks within 24 hours of a referral) with positive symptomatic outcomes for those whose early presentation does not involve aggressive behaviour (Bergström et al., 2017).

Finally, participants rarely talked about their role in isolation, often seeing themselves as part of a team of carers, therefore, shared interventions could facilitate discussion and reduce individualised senses of stigma. For example, couples counselling could be a source of support for both parents.

\section{Individual-level implications.}

Although carer support groups can be a helpful forum, father specific alternatives may be useful. Individual therapy can be accessed through primary care services; however, they tend to have thresholds, which carers may not meet. Therefore, a pathway for male and female carers could be agreed between services, in line with Kuipers' (2010) suggestions.

Alternatively, whether emotional expressions are articulate or not, given other studies identify that men express emotions differently and are reluctant to seek support (Sayers \& 
Splander, 2016), interventions that step beyond clinics and therapy rooms could be considered. This might be crucial given other studies state that men feel stigmatised being seen in clinic settings, are unwilling to talk to female health professionals and are confused by the jargon and language used (McKeown et al., 2015). Whilst not directly relevant to the needs of carers, Splander et al. (2013) used a football metaphor and football venues to deliver a non-clinical, group-based therapeutic intervention for men with mental health needs in the UK. The relaxed atmosphere and football analogy enabled attendees to engage in mutually supportive dialogues with each other; this fits with father's identification as a carer rather than a person in need of therapy.

\section{Limitations and future research}

In line with the IPA methodology, this study's small sample size limits generalisability. Further, the researchers are female exploring male experiences of fatherhood. It was important to maintain awareness of potential bias and this was addressed throughout the research via reflective discussions and diaries. It should be noted that a strength of the study was its methodology which answered the research question and identified consistent themes across the transcripts.

Addressing the following limitations could support the development of future research. Firstly, all fathers were recruited from carer support groups and were invested in their caring role; extending research to experiences of fathers who are not linked into carer supports forums or who have no contact with services, may widen the understanding of fathers' experiences. Additionally, according to occupations many participants appeared to be from higher socioeconomic groups, thus, recruiting more fathers who are unemployed or in lower paid jobs may also broaden understanding. 
Secondly, six of the seven participants were still married to the mother of the child they cared for. It emerged that there was a strong sense of unity between participants and their wives, which generally enabled and supported fathers in their caring role. Future studies could focus on fathers who are no longer with the mother of the child they care for; who are single or who have a different partner.

Thirdly, all participants were the biological father of the child they cared for, except one participant who was a step-father caring for two step-sons with psychosis; exploring the caring experiences of non-biological parents or step-parents (mothers and fathers), could be another aspect investigated by future research.

Fourthly, six of the seven participants cared for a son which may have influenced the results and reflected an enduring outcome of the father-son bond. Only one participant cared for his daughter who also had Autism Spectrum Disorder, limiting understanding of the experiences of fathers caring for daughters with psychosis. Extending research to fathers' experiences of caring for a daughter with psychosis would be useful. Moreover, a study looking at parents caring for more than one child with psychosis-related difficulties, would provide greater understanding and insight into the caring role and how parents make sense of their caring experiences, with the differing needs of their children.

Finally, only one participant identified as coming from an ethnic minority background limiting generalisability to other ethnic groups. It would be helpful to understand the caring experiences of fathers from ethnic minority groups living in the UK, given the higher incidence of psychosis in BME populations (Kirkbride et al., 2012). This would offer additional insights into how culture and ethnicity influence fathers' caring experiences and how fathers from these populations could be better supported, particularly for immigrant populations within the UK. For example, one study in India highlighted that fathers appeared more distant in caring for a child with psychosis and less impacted by stigma compared to 
mothers; there was also an unrelenting expectation from one male participant for mothers to fulfil certain expected duties (Koschorke et al., 2017).

Given the sample may reflect the contexts of the geographical areas they were recruited from, the study could be carried out in different areas of the UK to see if there was a difference in fathers' lived experiences based on locality.

\section{Acknowledgements}

We thank the participating fathers, carers' groups and the University of Hertfordshire for their support of this study.

\section{Disclosure of interest}

The authors report no conflict of interest. 


\section{References}

Bergström, T., Alakare, B., Aaltonen, J., Mäki, P., Köngäs-Saviaro, P., Taskila, J.J. \& Seikkula, J. (2017). The long-term use of psychiatric services within the Open Dialogue treatment system after first-episode psychosis. Psychosis: Psychological, Social and Integrative Approaches, 9 (4), 310-321.

Cabrera, N., Tamis-LeMonda, C. S., Bradley, R. H., Hofferth, S., \& Lamb, M. E. (2000). Fatherhood in the twenty-first century. Child Development, 71 (1), 127-136.

Chen, F., \& Greenberg, J.S. (2004). A positive aspect of caregiving: The influence of social support on caregiving gains for family members of relatives with schizophrenia. Community Mental Health Journal, 40 (5), 423-435.

Darmi, E., Bellali, T., Papazoglou, I., Karamitri I., \& Papadatou, D. (2017). Caring for an intimate stranger: parenting a child with psychosis. Journal of Psychiatric and Mental Health Nursing, 24 (4),194-202.

Doucet, A. (2004). "It's almost like I have a job, but I don't get paid": Fathers at home reconfiguring work, care, and masculinity. Fathering, 2, 277-303.

Hickman, G., Newton, E., Fenton, K., Thompson, J., Boden, Z.V., \& Larkin, M. (2016). The experiential impact of hospitalisation: Parents' accounts of caring for young people with early psychosis. Clinical Child Psychology and Psychiatry, 21 (1):145-55. doi: $10.1177 / 1359104515581716$.

Hinshaw, S. P. (2005). The stigmatisation of mental illness in children and parents: Developmental issues, family concerns, and research needs. Journal of Child Psychology and Psychiatry, 476 (7), 714-734.

Kingston, C., Onwumere, J., Keen, N., Ruffell, T., \& Kuipers, E. (2015). Posttraumtic stress symptoms (PTSS) in caregivers of people with psychosis and associations with caregiving experiences. Journal of Trauma and Dissociation, 17 (3), 307-321. 
Kirkbride, J. B., Errazuriz, A., Croudace, T. J., Morgan, C., Jackson, D., Boydell, J., \& Jones, P. B. (2012). Incidence of schizophrenia and other psychoses in England, 1950-2009: a systematic review and meta-analyses. PLOS One, 7 (3).

Koschorke, M., Padmavati, R., Kumar, S., Cohen, A., Weiss, H.A., Chatterjee, S., Pereira, J., Naik, S., John, S., Dabholkar, H., Balaji, M., Chavan, A., Varghese, M., Thara, R., Patel, V. \& Thornicroft, V. (2017). Experiences of stigma and discrimination faced by family caregivers of people with schizophrenia in India. Social Science \& Medicine, 178, 66-77.

Kuipers, E. (2010). Time for a separate psychosis caregiver service? Journal of Mental Health, 19 (5), 401-404.

Lamb, M. E. (2000). The history of research on father involvement: An overview. Marriage \& Family Review, 29 (2-3), 23-42

Larkin, M., \& Thompson, A.R. (2012). Interpretative Phenomenological Analysis in Mental Health and Psychotherapy Research. In D. Harper, \& R. Thompson (Eds.), Qualitative Research Methods in Mental Health and Psychotherapy: A Guide for Students and Practitioners (pp. 39-54). Chichester: John Wiley \& Sons, Ltd.

Magliano, L., Fadden, G., Madianos, M., de Almeida, J. M., Held, T., Guarneri, M., Marasco, C., Tosini, P., \& Maj, M. (1998). Burden on the families of patients with schizophrenia: results of the BIOMED I study. Social Psychiatry and Psychiatric Epidemiology, 33 (9), 405-12.

McAuliffe, R., O'Connor, L., \& Meagher, D. (2014). Parents' experience of living with and caring for an adult son or daughter with schizophrenia at home in Ireland: a qualitative study. Journal of Psychiatric Mental Health Nursing, 21 (2),145-53. 
McCann, T.V., Lubman, D.I., \& Clark, E. (2011). First-time primary caregivers' experience of caring for young adults with first-episode psychosis. Schizophrenia Bulletin, 37 (2), $381-8$

McKeown, M., Roy, A., \& Spandler, H. (2015). 'You'll never walk alone': Supportive social relations in a football and mental health project. International Journal of Mental Health Nursing, 24, 360-369.

National Institute of Health and Care Excellence (NICE) (2014). Psychosis and Schizophrenia in adults: treatment and management (178). London: National Institute for Health and Care Excellence.

Onwumere, J., Kuipers, E., Bebbington, P., Dunn, G., Fowler, D., Freeman, D., \& Garety, P. (2008). Caregiving and illness beliefs in the course of psychotic illness. The Canadian Journal of Psychiatry, 53 (7), 460-468.

Onwumere, J., Shiers, D., \& Chew-Graham, C. (2016). Understanding the needs of carers of people with psychosis in primary care. The British Journal of General Practice: The Journal of the Royal College of General Practitioners, 66 (649), 400-401.

Raymond, K.Y., Willis, D.G., \& Sullivan-Bolyai, S. (2017). Parents Caring For Adult Children With Serious Mental Illness. Journal of the American Psychiatric Nurses Association, 23 (2), 119-132.

Rochlen, A. B., McKelley, R. A., \& Whittaker, T. A. (2010). Stay-at-home fathers' reasons for entering the role and stigma experiences: A preliminary report. Psychology of Men \& Masculinity, 11 (4), 279-285.

Roick, C., Heider, D., Bebbington, P.E., Angermeyer, M.C., Azorin, J.M., Brugha, T.S., et al. (2007). Burden on caregivers with schizophrenia: comparison between Germany and Britain. British Journal of Psychiatry, 190, 333-38. 
Royal College of Psychiatrists (2019). National Clinical Audit of Psychosis: National Report for the Early Intervention in Psychosis Spotlight Audit 2018/2019. London: Healthcare Quality Improvement Partnership. Available from: www.rcpsych.ac.uk/NCAP

Sayers P., \& Spandler H. (2016). It's a Goal: A Football-Based Mental Health Programme. In D. Conrad., \& White A. (eds) Sports-Based Health Interventions. Springer: New York.

Schizophrenia Commission. (2012). The Abandoned Illness: A Report from the Schizophrenia Commission. Rethink Mental Illness. Retrieved 9 November 2016 from $\quad$ https://www.sussex.ac.uk/webteam/gateway/file.php?name=tsc-executivesummary1.pdf\&site $=75$

Sharma, B. (2018). Fathers' experiences of caring for an adult child with psychosis: A qualitative study (Doctoral dissertation). Retrieved from https://uhra.herts.ac.uk/handle/2299/21279

Sharma, N., Chakrabarti, S., \& Grover, S. (2016). Gender differences in caregiving among family-caregivers of people with mental illnesses. World Journal of Psychiatry, 6 (1), 7.

Smith, J.A., Flowers, P., \& Larkin, M. (2009). Interpretive Phenomenological Analysis: Theory, Method and Research. London: Sage.

Spandler, S., McKeown, M., Roy, A., \& Hurley, M. (2013). Football metaphor and mental well-being: An evaluation of the It's a Goal! Programme. Journal of Mental Health, $22(6), 544-554$.

Wall, G. \& Arnold, S. (2007). How Involved is Involved Fathering? An Exploration of the Contemporary Culture of Fatherhood. Gender and Society, 21 (4), 508-527. 
Yardley, L. (2008). Demonstrating Validity in Qualitative Psychology. In J.A. Smith (Ed.). Qualitative Psychology: A Practical Guide to Research Methods (2nd Ed., pp. 235251). London: Sage.

Yesufu-Udechuku, A., Bronwyn, H., Mayo-Wilson, E., Young, N., Woodhams, P., Shiers, D., Kuipers, E. \& Kendall, T. (2015). Interventions to improve the experience of caring for people with severe mental illness: systematic review and meta-analysis. The British Journal of Psychiatry, 206, 268-274. 